\title{
Isolation and characterization of SYS genes from yeast, multicopy suppressors of the functional loss of the transport GTPase Ypt6p
}

\author{
Miki Tsukada and Dieter Gallwitz* \\ Max Planck Institute for Biophysical Chemistry, Department of Molecular Genetics, PO Box 2841, D-37018 Göttingen, Germany \\ *Author for correspondence (e-mail: dgallwi1@gwdg.de)
}

\section{SUMMARY}

In Saccharomyces cerevisiae, the YPT6 gene encodes the homologue of the mammalian Rab6 protein found in the Golgi apparatus. Deletion of YPT6 in yeast produces a phenotype showing temperature-sensitive growth and partial missorting of the vacuolar enzyme, carboxypeptidase Y. To identify proteins that might: (1) interact with Ypt6p; or (2) act in the same pathway, we have isolated four multicopy suppressors, named SYS1, SYS2, SYS3 and SYS5, that can complement the temperature-sensitive growth phenotype of the ypt6 null mutant. On high expression, these genes are also able to partially suppress the missorting of carboxypeptidase Y. SYS2 on a multicopy plasmid suppresses in addition the temperature-sensitive phenotype of sec7-1, a mutant defective in transport

\section{INTRODUCTION}

Small GTP-binding proteins belonging to the Ras superfamily function in a variety of cellular processes, including signaltransduction, cytoskeletal organization, and protein transport. Individual members of the Ypt/Rab family of GTPases are believed and have been shown to regulate defined steps in vesicular membrane traffic, and they are associated with distinct subcompartments of the exocytotic and endocytotic pathways (Grabowski et al., 1995; Zerial and Stenmark, 1993, for review).

One of these small GTP-binding proteins, Ypt6p of S. cerevisiae, was isolated several years ago (Hengst, 1992). It is a homologue of the Schizosaccharomyces pombe Ryh1p (Hengst et al., 1990) and the mammalian Rab6p (Goud et al., 1990) with whom it shares $60 \%$ and $76 \%$ of identical sequence. Ypt6p is not essential for cell viability but disruption of YPT6 results in temperature-sensitive $\left(\mathrm{Ts}^{-}\right)$cell growth. The mammalian Rab6p has been localized to the medial and transGolgi cisternae as well as to the trans-Golgi network (TGN) (Goud et al., 1990; Antony et al., 1992). It has been argued that Rab6p might be involved in intra-Golgi retrograde transport (Martinez et al., 1994). The high sequence identity and the fact that the mammalian Rab6 gene was able to complement the $\mathrm{Ts}^{-}$phenotype of the ypt6 null mutant in yeast, together with the partial missorting of vacuolar proteins carboxypeptidase $\mathrm{Y}$ (CPY) caused by the deletion of YPT6 (Hengst, 1992; L. between and from the Golgi compartment. Gene disruption of SYS1 and SYS2 did not result in significant growth defects. However, deletion of SYS1 and/or SYS2 in the ypt6 null mutant enhances defects in vacuolar protein sorting and in cell growth. Whereas protein secretion was not significantly affected in these mutants, the processing of $\alpha$ factor precursor by the Kex2 protease was inhibited, suggesting a function of YPT6 and its null mutant suppressors in transport between the late Golgi and a prevacuolar, endosome-like compartment.

Key words: Golgi transport, Ypt GTPase, Saccharomyces cerevisiae, SYS gene

Hengst and D. Gallwitz, unpublished), indicate that Ypt6p might also have a Golgi-associated function.

To identify proteins which directly interact with Ypt6p or fulfill a related function, we decided to screen for genes which on high expression could rescue ypt6 deletion mutants. The approach to search for multicopy suppressors of $S$. cerevisiae mutants defective in vesicular trafficking has already produced many significant results. Dascher et al. (1991) successfully isolated three multicopy suppressors, SLY2/SEC22, $S L Y 12 / B E T 1$ and SLY41, that can rescue the deletion of YPT1, an essential gene encoding a small GTPase with a function in ER-to-Golgi protein transport. Searches for multicopy suppressors of a temperature-sensitive secl mutation led to the isolation of SSO1 and $\mathrm{SSO} 2$ encoding yeast homologues of mammalian syntaxin that are required for docking of Golgiderived transport vesicles to the plasma membrane (Aalto et al., 1993). Likewise, Brennwald et al. (1994) have identified the SEC 9 gene, originally isolated as one of the genes required for a late step of the secretory pathway (Novick et al., 1981), as a multicopy suppressor of a Sec4 GTPase effector domain mutant. They showed that the product of SEC9 is the yeast counterpart of the mammalian SNAP-25 protein (Oyler et al., 1989) which is a component of the docking/fusion complex of secretory vesicles in neuronal cells (reviewed by Rothman, 1994; Söllner, 1995).

We here describe the isolation of four multicopy suppressor genes, SYS1, SYS2, SYS3 and SYS5, that can rescue phenotypic 
alterations of ypt6 null mutants. In this report, two of these genes, SYS1 and SYS2, will be discussed in more detail.

\section{MATERIALS AND METHODS}

\section{Strains, growth conditions and genetic methods}

The genotypes of the yeast strains used in this study are listed in Table 1. Yeast strains were grown in $1 \%$ yeast extract (Gibco, Gaithersburg), 2\% peptone 140 (Gibco, Gaithersburg), 2\% glucose (YEPD), or in synthetic glucose medium (SD) supplemented as necessary (Rose et al., 1990). For synthetic fructose medium (SF), glucose was replaced by $2 \%$ fructose. Solid media were prepared by adding $2 \%$ agar (Gibco, Gaithersburg). Standard genetic methods, such as crossing, sporulation of diploids and tetrad dissection, and auxotrophic selections of diploids were performed as described by Rose et al. (1990). Lithium acetate transformation of yeast cells was performed as previously described (Ito et al., 1983).

\section{Isolation and identification of SYS genes}

A yeast genomic library in the multicopy shuttle vector YEp13 (Dascher et al., 1991) was used to screen for suppressor genes. The suppressor gene-containing genomic fragments were sequenced from the single BamHI site of the vector YEp13, into which the fragments were inserted. The DNA sequences were compared with the sequence data in the EMBL/GenBank/DDBJ databases and localized on specific chromosomes. Several regions containing predicted open reading frames (ORFs) on each identified chromosome were subcloned into the vector pRS325 (this study, see below). The resulting plasmids were used for re-transformation to determine which ORF on the isolated genomic fragments was responsible for the suppressor function.

\section{Construction of recombinant plasmids}

The $2.5 \mathrm{~kb}$ Bam HI/EcoRV fragment containing the entire YPT6 gene (Hengst, 1992) was cloned into the BamHI and EcoRV sites of pBluescriptIIKS $^{+}$(Stratagene). A $B g l \mathrm{II}$ site was created $0.3 \mathrm{~kb}$ behind the stop codon of YPT6 in this plasmid for further experimental use. The $1.0 \mathrm{~kb} \mathrm{BglI} / H h a \mathrm{I}$ fragment containing SYS1, whose DNA ends were treated with T4 DNA polymerase, was cloned into the SmaI site in pRS325. pRS325 was constructed as follows: a $2.2 \mathrm{~kb}$ EcoRI fragment containing $2 \mu$ yeast DNA was isolated from YEp24 (Botstein et al., 1979) and blunt-end ligated into the filled AatII site in pRS305 (Sikorski and Hieter, 1989). To construct pRS325-SYS2 and pRS315-SYS2, the $1.9 \mathrm{~kb} E c o R I / X h o I$ fragment containing the $S Y S 2$ gene was treated with T4 DNA polymerase and cloned into the SmaI site of either pRS315 or pRS325.

\section{Gene disruptions}

Single step disruption of chromosomal genes were done with linear DNA fragments. Part of the protein-coding region of the gene was removed and replaced by a yeast marker gene (LEU2, HIS3 or URA3). From the YPT6 gene-containing $2.5 \mathrm{~kb} B a m \mathrm{HI} / E c o \mathrm{RV}$ DNA fragment in pBluescriptIIKS ${ }^{+}$, a $1.0 \mathrm{~kb} A f I I I / B g l I I$ fragment containing the entire YPT6 protein-coding region $(-70$ to +340$)$ was removed and replaced by a $1.4 \mathrm{~kb} \mathrm{SspI/NciI}$ fragment harbouring the HIS3 gene. The $B g l I I$ site was introduced by site-directed mutagenesis. As YPT6 is a non-essential gene, its disruption was performed by transforming the haploid strain GFUI-5B with a $2.8 \mathrm{~kb}$ BamHI/EcoRV ypt6::HIS3 fragment which contained $1.0 \mathrm{~kb}$ and $0.4 \mathrm{~kb}$ of sequence extending $5^{\prime}$ and $3^{\prime}$ from the deletion end points. From the SYS1 gene residing

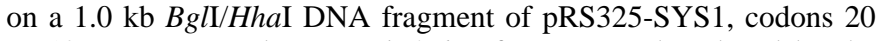
to 54 were removed as a $B g / I \mathrm{I} /$ NheI fragment and replaced by the HIS3 gene as described for YPT6. Likewise, codons 74 to 293 of SYS2 were removed as a $\mathrm{NcoI} / \mathrm{MscI}$ fragment from pRS315-SYS2, a recombinant plasmid harbouring the suppressor gene on a $1.9 \mathrm{~kb}$
EcoRI/XhoI DNA fragment, and replaced by HIS3. To disrupt one copy of either SYS1 or SYS2 in the diploid his $3 / h i s 3$ strain GFUI5B/9D, competent cells were transformed with either $2.2 \mathrm{~kb}$ NruI/BamHI sys $1:: H I S 3$ or a $2.2 \mathrm{~kb}$ StuI/BamHI sys $2:: H I S 3$ DNA fragment. In all cases, correct integration was verified by Southern blot analysis using the ECL system (Amersham). For double disruptions, parts of the protein-coding regions of SYS1 or SYS2 were also replaced by $L E U 2$ on a $2.2 \mathrm{~kb} \mathrm{HpaI}$ fragment. A haploid ypt6 null mutant (disrupted with HIS3) was then transformed with either a 2.9 $\mathrm{kb} \mathrm{NruI/BamHI}$ sys $1:: L E U 2$ fragment or a $2.9 \mathrm{~kb}$ BamHI/StuI sys $2:: L E U 2$ fragment. For construction of the triple null mutant, the protein-coding region of YPT6 on pBluescriptIIKS ${ }^{+}$-YPT6 was disrupted with URA3. A $1.1 \mathrm{~kb}$ HindIII fragment containing the URA3 gene was isolated from YEp24, and was treated with T4 DNA polymerase. The fragment was then blunt-end ligated into the filled $\mathrm{A} f \mathrm{II}$ and $B g l I I$ sites in pBluescriptIIKS ${ }^{+}$-YPT6 (see above). The resulting plasmid was cut with BamHI and DraI and the resulting $2.2 \mathrm{~kb}$ BamHI/DraI fragment was used to replace one copy of YPT6 in the diploid strain 5361-1A10A which is homozygous with respect to the disruption of SYS1 and SYS2. Transformants were sporulated, subjected to tetrad analysis and the triple null mutants were identified guided by the linked marker genes.

\section{Halo assay}

Halo assays for measuring secreted active $\alpha$-pheromone were performed by spotting $\alpha$-pheromone-producing strains on a lawn of the supersensitive indicator yeast strain RC-898 (see Table 1) as described (Julius et al., 1983). MAT $\alpha$ strains with different gene deletions were grown to stationary phase and after appropriate dilution, $5 \mu \mathrm{l}$ cultures were spotted onto a lawn of the supersensitive strain and cultured for 2 to 3 days at $30^{\circ} \mathrm{C}$.

\section{Assay for secreted carboxypeptidase $Y$}

Extracellular missorted CPY was assayed as by Horazdovsky et al. (1994). Plasmid pBHY11 (Horazdovsky et al., 1994) was used to construct pMTY11 (CPY-Inv URA3) which was used to integrate a CPY-invertase gene fusion into some yeast strains. pMTY11 was constructed by ligating a SpeI/XhoI fragment containing the CPYinvertase fusion genes from pBHY11 and integration plasmid pRS306 (Sikorski and Hieter, 1989) cut with SpeI and XhoI. pMTY11 was treated with EcoRV in order to linearize the plasmid in the middle of the URA3 locus in the plasmid. The resulting fragment was used for transformation and integration at the chromosomal ura3-52 locus.

\section{Radiolabelling and immunoprecipitation}

Spheroplasts were prepared and labelled as described by Robinson et al. (1988). Cells of the various strains were grown overnight at $30^{\circ} \mathrm{C}$ in YEPD medium to $A_{600}$ of about 0.6 to 1.2. Six $A_{600}$ of cells were harvested, suspended in $0.1 \mathrm{M}$ Tris-sulfate (pH 9.4) containing $10 \mathrm{mM}$ dithiothreitol, and incubated at $30^{\circ} \mathrm{C}$ for 5 minutes. After centrifugation, cells were suspended in $1 \mathrm{ml}$ semi-minimal medium (SMM) that was adjusted to $\mathrm{pH} 7.5$ and that contained $1.2 \mathrm{M}$ sorbitol. SMM used here contained $0.1 \% \quad \mathrm{KH}_{2} \mathrm{PO}_{4}, 0.1 \% \mathrm{NH}_{4} \mathrm{Cl}, 0.02 \% \mathrm{CaCl}_{2} 2 \mathrm{H}_{2} \mathrm{O}$, $0.06 \% \mathrm{MgCl}_{2} \cdot 6 \mathrm{H}_{2} \mathrm{O}, 0.05 \% \mathrm{NaCl}, 0.3 \%$ yeast extract, $0.002 \%$ uracil, $0.002 \%$ adenine sulfate and amino acids if necessary. Zymolyase 100$\mathrm{T}$ (Seikagaku Kogyo) was added to a final activity of 5 units, and the cultures were incubated at $30^{\circ} \mathrm{C}$ for 10 minutes. Spheroplasts were pelleted, washed twice with SMM containing $1.2 \mathrm{M}$ sorbitol, and resuspended in $250 \mu \mathrm{l} \mathrm{SMM-sorbitol} \mathrm{containing} 1 \mathrm{mg} / \mathrm{ml}$ of ovalbumin. After 30 minutes of incubation, Tran ${ }^{35}$ S-label (ICN, Meckenheim) was added to $150 \mu \mathrm{Ci}$ and the spheroplasts were pulsed for 15 minutes followed by a chase of 30 minutes with methionine and cysteine $(0.5 \mathrm{mg} / \mathrm{ml}$ each). To terminate the reaction, the $250 \mu \mathrm{l}$ samples were placed on ice and added to $\mathrm{NaN}_{3}$ and PMSF (final concentration $10 \mathrm{mM}$ and $1 \mathrm{mM}$ ). The labelled culture was separated into spheroplast (intracellular) and medium (extracellular) fractions. The spheroplast pellet was resuspended in $100 \mu 1$ 1\% SDS and was heated 
at $95^{\circ} \mathrm{C}$ for 3 minutes. $250 \mu \mathrm{l}$ of medium fraction was added to $10 \mu \mathrm{l}$ $10 \% \mathrm{SDS}$ and heated at $95^{\circ} \mathrm{C}$ for 3 minutes. After 3 minutes of centrifugation, the supernatant was diluted with the following ice-cold buffer to a final volume of $1 \mathrm{ml}$ : phosphate-buffered saline (PBS), $0.1 \%$ Triton $\mathrm{X}-100,1 \mathrm{mM}$ PMSF, $1 \mathrm{mg}$ ovalbumin, $1 \mathrm{mM}$ EDTA, $1 / 500$ volume of proteinase inhibitor cocktail $(14 \mathrm{mg} / \mathrm{ml}$ aprotinin, 5 $\mathrm{mg} / \mathrm{ml}$ leupeptin, $20 \mathrm{mg} / \mathrm{ml}$ trypsin inhibitor, $5 \mathrm{mM}$ E64) and 1/250 volume of $1 \mathrm{M}$ benzamidin. For immunoprecipitation, $5 \mu \mathrm{l}$ of anticarboxypeptidase $\mathrm{Y}(\mathrm{CPY})$ antiserum and $5 \mathrm{mg}$ of Protein ASepharose CL-4B (Pharmacia Biotech) were added and incubated overnight at $4^{\circ} \mathrm{C}$. After collecting the beads by centrifugation, the beads containing anti-CPY immunocomplexes were washed three times with $1 \mathrm{ml}$ ice-cold wash buffer $(10 \mathrm{mM}$ Tris-HCl, $\mathrm{pH} \mathrm{8.0,0.1 \%}$ SDS, $0.1 \%$ Triton X-100 and 0.1 mM EDTA) and resuspended in 50 $\mu 12 \times$ Laemmli sample buffer. The immunoprecipitates were heated at $95^{\circ} \mathrm{C}$ for 5 minutes and separated by SDS-PAGE on $8 \%$ gels. After electrophoresis the gels were fixed, treated with Amplify (Amersham) according to the manufacturer's instructions, dried and exposed to Kodac X-Omat AR films at $-70^{\circ} \mathrm{C}$.

For immunoprecipitation of $\alpha$-pheromone, $\alpha$ cells of the various strains were prepared as described for immunoprecipitation of CPY except that cells were not spheroplasted. Cells were suspended in 250 $\mu 1$ SMM containing $1 \mathrm{mg} / \mathrm{ml}$ of ovalbumin. After 30 minutes of incubation, Tran ${ }^{35} \mathrm{~S}$-label (ICN, Meckenheim) was added to $250 \mu \mathrm{Ci}$ and the cells were pulsed for 30 minutes at $30^{\circ} \mathrm{C}$. Culture media were collected by centrifugation and after protein denaturation in SDS and dilution in the same buffer as described above, immunoprecipitation was performed with $6 \mu \mathrm{l}$ of anti- $\alpha$-pheromone antiserum and $5 \mathrm{mg}$ of Protein A-Sepharose CL-4B (Pharmacia Biotech). After overnight incubation at $4{ }^{\circ} \mathrm{C}$, the beads containing anti- $\alpha$-pheromone immunocomplexes were washed and treated as described above and separated by SDS-PAGE on $15 \%$ gels.

\section{Electron microscopy}

Electron microscopy was performed as previously described (Ossig et al., 1991).

\section{RESULTS}

\section{Identification and isolation of multicopy suppressors of a ypt6 null mutant}

In order to isolate genes that can suppress the temperaturesensitive phenotype of the ypt6 null mutants, we transformed a ypt6 deletion strain with a yeast genomic library on the multicopy plasmid YEp13. Transformants on selective plates (-Leu) were incubated for one day at $30^{\circ} \mathrm{C}$ and thereafter at $37^{\circ} \mathrm{C}$. Of approximately 63,000 transformants, 70 were able to grow at $37^{\circ} \mathrm{C}$. Plasmids were isolated and used for re-transformation after amplification in Escherichia coli. Of these isolated plasmids, 27 showed reproducible suppressor activity. Restriction analysis revealed that 19 of these plasmids contained the authentic YPT6 gene. Of the remaining eight plasmids, three contained the same genomic region, and of the remaining five plasmids, two were duplicates. Finally, four plasmids that contained different inserts were identified. As shown in Fig. 1, at $37^{\circ} \mathrm{C}$ ypt6 null mutants transformed with the recombinant plasmids were rescued from growth defect comparably to ypt6 null mutants which had been transformed with single- or multi-copy plasmids bearing YPT6. The newly isolated four genes, competent to suppress the $\mathrm{Ts}^{-}$phenotype of the ypt6 null mutant, were named SYS1, 2, 3, and 5 (for suppressor of $\underline{\text { Ypt }} \underline{\text { six }}$ ).

Disruption of YPT6 results in the partial missorting of the vacuolar protease CPY (Hengst, 1992; L. Hengst and D. Gallwitz, unpublished). CPY is transported to the vacuole via the secretory pathway. In wild-type cells, the enzyme is found in three forms, the core-glycosylated ER precursor p1, the Golgi p2 form and the enzymatically active mature form which is found in the vacuole (reviewed by Klionsky et al., 1990; Raymond et al., 1992a; Stack et al., 1995). Sorting defects of

Table 1. Strains used in this study

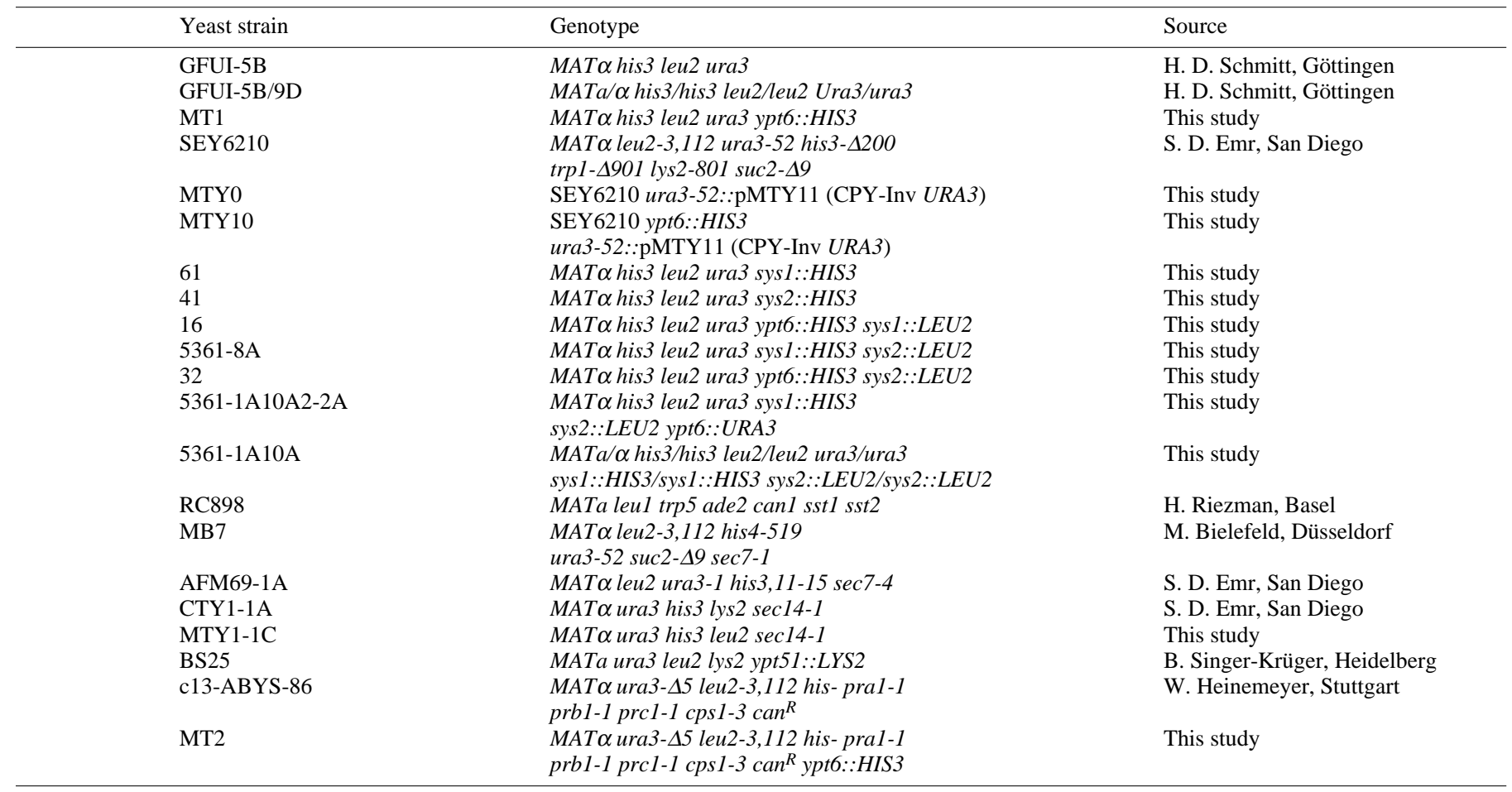




\section{$30^{\circ} \mathrm{C}$ SD (-Leu)}

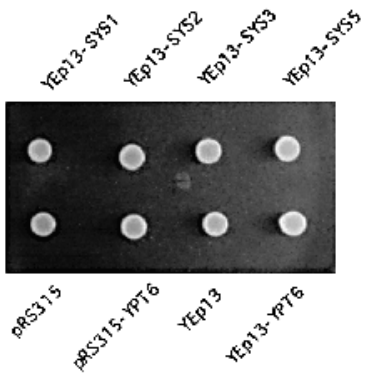

$37^{\circ} \mathrm{C}$ SD (-Leu)

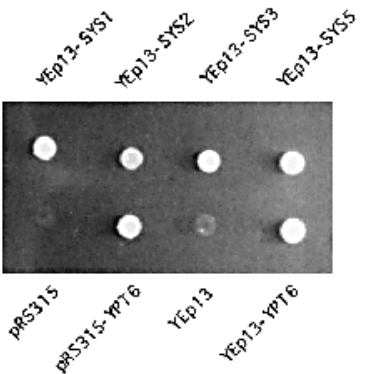

Fig. 1. Suppression of the temperature-sensitive growth defect of a ypt6 null mutant. MT1 ( $\Delta y p t 6)$ was transformed with the multicopy (YEp13) or singlecopy plasmid (pRS315) without insert or with DNA fragments carrying the genes indicated. Transformants were spotted onto SD (-Leu) medium and incubated at $30^{\circ} \mathrm{C}$ or $37^{\circ} \mathrm{C}$.

p2CPY lead to its secretion into the medium. As is typical for all vps (vacuolar protein sorting) mutants (reviewed by Klionsky et al., 1990; Raymond et al., 1992a; Stack et al., 1995), the p2 form of CPY is also partially secreted in ypt6 null mutants.

We therefore sought to investigate whether the missorting of p2CPY in ypt6 null mutants can be suppressed by high expression of SYS genes. To test this, we used a CPY-invertase gene fusionbased system that is highly sensitive in detecting CPY missorting and secretion (Horazdovsky et al., 1994). In wild-type cells, the CPY-invertase fusion protein is delivered to the vacuole due to the localization signal contained in the CPY portion of the fusion protein. However, in mutant cells, the fusion protein is missorted and secreted. The extracellular secreted CPY-invertase activity can be easily detected by a simple colorimetric plate assay based on the oxidation of glucose formed: invertasesecreting cells turn dark brown. A ypt6/suc2 null mutant with this CPY-invertase construction synthesizing the CPY-invertase fusion protein from a chromosomally located gene (see Materials

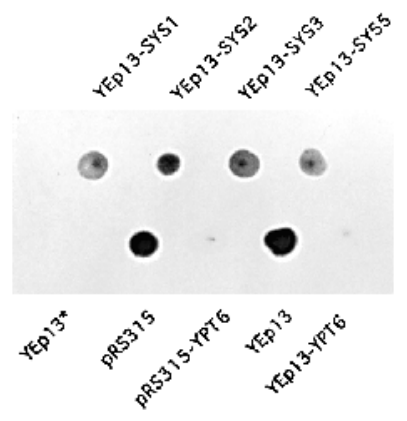

Fig. 2. Partial suppression of CPY-invertase missorting in a $\Delta y p t 6$ strain through high expression of $S Y S$ genes. MTY10 ( $\Delta y p t 6 / s u c 2$, CPY-Inv URA3) was transformed with multicopy plasmids carrying the genes as indicated. MTY0 (YPT6, CPY-Inv URA3), transformed with insert-free YEp13 (*), was used as control. $\mathrm{Ura}^{+} / \mathrm{Leu}^{+}$ transformants were selected, spotted onto SF (-Leu) medium and incubated overnight at $30^{\circ} \mathrm{C}$. Colonies secreting the CPY-invertase fusion protein, such as ypt6 deletion strains with the vector alone, turned brown in a colour assay according to the method of Horazdovsky et al. (1994). Colonies which do not secrete the CPYinvertase fusion protein (YPT6 or $\triangle y p t 6$ carrying YPT6 on a singleor multicopy plasmid) remain white.

and Methods) was transformed with the plasmids carrying either one of the SYS genes. The ypt6 null mutant with complementing plasmids produces white colonies due to the correct vacuolar localization of the CPY-invertase fusion protein. As shown in Fig. 2, colonies of transformants carrying YPT6 on multi- or single-copy plasmids turned white, whereas transformants carrying $2 \mu$-based plasmids with either SYS1, SYS3 or SYS5 gave rise to light brown colonies. This suggests that the missorting of the fusion protein was partially suppressed. Mutants carrying plasmids with SYS2 were significantly less effective in rescuing the ypt6 null mutant from missorting CPY.

\section{Sequence and chromosomal localization of SYS1 and SYS2}

Sequence analysis of the ends of the isolated genomic fragments revealed that SYS1 and SYS2 were localized on chromosomes whose complete sequences have been made public. After subcloning and re-transformation, the ORF of SYS1 was identified as YJR83.17 on chromosome $\mathrm{X}$ and the ORF of SYS2 was shown to be YCL37C on chromosome III (Oliver et al., 1992; Koonin et al., 1994). The sequence of YJR83.17 in the EMBL/GenBank/DDBJ databases corresponded perfectly to the nucleotide sequence of $S Y S I$ analysed in this study (data not shown). The deduced amino acid sequence predicts a protein of $23.7 \mathrm{kDa}$ which is hydrophobic over its entire length except for the N- and C-terminal regions. Four hydrophobic amino acid stretches of Sys $1 p$ are predicted to be transmembrane domains (Fig. 3A). The two predicted transmembrane domains residing in the C-terminal half of Sys1p are comparatively short and rich in phenylalanine, which has been suggested to be characteristic for Golgi membrane proteins (Bretscher and Munro, 1993; Banfield et al., 1995).

A.

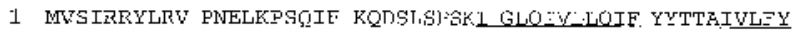

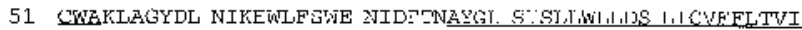

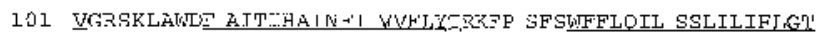

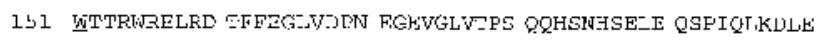

$$
\begin{aligned}
& 20150 T^{*}
\end{aligned}
$$

B.
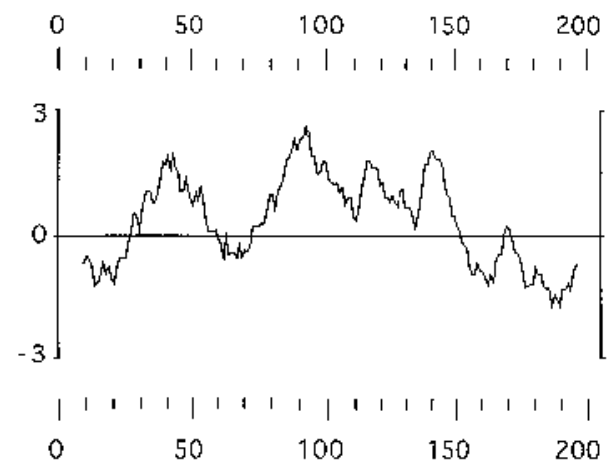

Fig. 3. Amino acid sequence of Sys1p. (A) The amino acid sequence of Sys $1 p$ as deduced from the DNA sequence. The predicted transmembrane domains determined according to the MEMSAT model (Jones et al., 1994) are underlined. GenBank accession number: SYS1, X87611. (B) Hydrophobicity profile of Sys1p. Hydrophobicity of Sys1p was determined according to the method of Kyte and Doolittle (1982) with a window of 18. 
The DNA sequence of SYS2 (GenBank accession number X59720) predicts a hydrophilic protein of $51.8 \mathrm{kDa}$. We have not resequenced the gene, whose protein product is significantly related to the Slf1 protein (GenBank accession number U30375) of unknown function.

\section{Disruption of YPT6, SYS1 and SYS2 in any combination has a synthetic inhibitory effect on cell growth}

To assess the functional role of Sys1p and Sys2p, null mutants of SYS1 and SYS2 were generated whereby a significant part of the protein-coding regions of both genes was deleted (described in Materials and Methods). Strains in which SYSI was disrupted were viable and had no significant growth defects. Disruption of SYS2 did not result in significant growth defects, either. The doubling time in YEPD of strains carrying disrupted SYS1 or SYS2 alleles was indistinguishable from the isogenic wild-type strain ( 90 minutes). These results demonstrate that neither SYS1 nor SYS2 is essential for cell viability or mitotic growth. In contrast to ypt6 disruption strains, sys 1 as well as sys 2 null mutants grew perfectly well at $37^{\circ} \mathrm{C}$.

To determine the functional overlap between Sys1p, Sys2p and Ypt6p, all possible pairs of double disruption mutants and the triple null mutant were constructed. To construct double mutants, each of the genes was disrupted with a selectable marker on a fragment that was used to replace the wild-type gene on the respective chromosome in haploid strains. To construct the ypt6/sysl and ypt6/sys2 null mutants, a $y p t 6:: H I S 3$ mutant was transformed with the fragment that contained either sys $1:: L E U 2$ or sys $2:: L E U 2$. The sys $1 /$ sys 2 double mutant was obtained by crossing haploid null mutants, followed by tetrad dissection. In all cases, correct chromosomal integration of the disruption constructs was verified by Southern blot analysis (data not shown). In contrast to single disruptions, all the double mutants showed a significant growth defect at $30^{\circ} \mathrm{C}$ (Fig. 4A). The doubling times of ypt6/sysl, sys $1 / s y s 2$ null mutants ( 150 minutes) and ypt6/sys 2 null mutants ( $\sim 120$ minutes) in YEPD at $30^{\circ} \mathrm{C}$ were prolonged with respect to that of the isogenic wild-type strain ( $\sim 90$ minutes). To obtain the ypt6/sys $1 /$ sys 2 triple null mutant, we transformed a homozygous diploid sys $1 /$ sys 2 deletion strain with a fragment containing the disrupted YPT6 gene (ypt6::URA3). After sporulation and tetrad dissection, it was observed that in each tetrad two spores formed large and the other two formed only very small colonies (Fig. 4B). After eight days of incubation at $25^{\circ} \mathrm{C}$, spores which grew slowly eventually formed colonies of sufficient size to be analyzed further. The defective growth phenotype always cosegregated with $\mathrm{Ura}^{+}$phenotype, suggesting that haploid progeny carrying the disrupted YPT6, that is the triple mutant, grew remarkably slower than the sys $1 /$ sys 2 double mutant. As shown in Fig. 4A, the ypt6/sys 1/sys 2 triple null mutant grew extremely slowly on incubation at $30^{\circ} \mathrm{C}$. The synthetic growth-defective phenotype described here could result from the lack of two or three different proteins acting in the same cellular process, as has been found in other cases (Salminen and Novick, 1987; Kaiser and Schekman, 1990).

\section{Maturation of $\alpha$-pheromone in ypt6/sys 1 and ypt6/sys1/sys2 null mutants is inhibited}

To investigate a possible role of Sys1p and Sys $2 p$ in intracellular protein transport, secretion of $\alpha$-pheromone, which passes
A

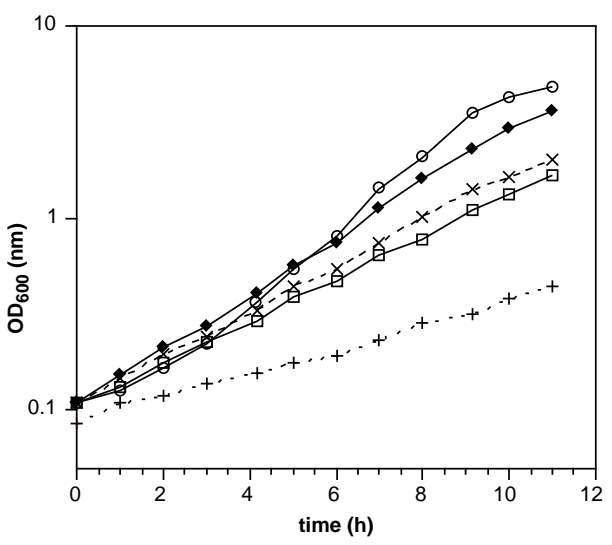

B
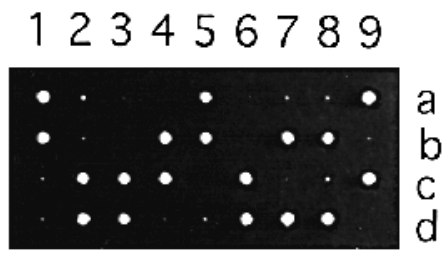

Fig. 4. Synthetic negative growth phenotype of double- and tripledeletion mutants. (A) Growth curves of wild-type (O), $\Delta y p t 6 /$ sys 1 $(\square), \Delta y p t 6 /$ sys $2(\bullet), \Delta$ sys $1 /$ sys $2(\times)$ and $\Delta y p t 6 /$ sys $1 /$ sys $2(+)$ strains. Precultures of corresponding strains were grown to stationary phase at $30^{\circ} \mathrm{C}$. Cells were diluted into fresh YEPD medium to an $A_{600}$ of about 0.01 and incubated overnight to an $A_{600}$ of about 2 to 3 . Cells were again diluted into fresh YEPD medium to an $A_{600}$ of about 0.1 and incubated at $30^{\circ} \mathrm{C}$. Cell growth was followed by measuring the optical density at $600 \mathrm{~nm}$. (B) Growth defect of a ypt6/sys 1/sys2 triple null mutant. One of two wild-type copies of YPT6 was replaced by the URA3 gene in a homozygous $\Delta$ sys $1 /$ sys 2 diploid strain to obtain the triple null mutant. The diploid strain was sporulated, the spores separated and cultured on an agar plate. The four spores from each of nine tetrads were placed at positions a-d. By following the markers linked to the disrupted genes, the triple null mutants were identified as tiny colonies.

the compartments of the secretory pathway, was tested by the halo assay with all deletion strains. The secretion of active $\alpha$ pheromone from a MAT $\alpha$ strain induces a $\mathrm{G}_{1}$ cell cycle arrest in cells of opposite mating type (MATa). The size of the halo correlates well with the amount of the secreted active $\alpha$ pheromone (Julius et al., 1983). According to this assay, the single deletion of either YPT6, SYS1 or SYS2 appeared to not interfere significantly with the secretion of $\alpha$-pheromone. However, the halo generated by the ypt6/sys 1 or the triple ypt6/sys 1/sys 2 deletion mutant, but not that of the sys1/sys 2 or the ypt6/sys 2 null mutant, was clearly smaller than the one generated by the isogenic wild-type strain (Fig. 5).

Since only functional, mature $\alpha$-pheromone can be detected by the halo assay, the reduction of halo-forming activity in mutant cells lacking both Ypt6p and Sys1p could result from either a secretion defect of functional $\alpha$-pheromone or an interference with $\alpha$-pheromone maturation. To address these possibilities, maturation of $\alpha$-pheromone was analysed. Normally, only mature $\alpha$-pheromone is secreted from cells into the 

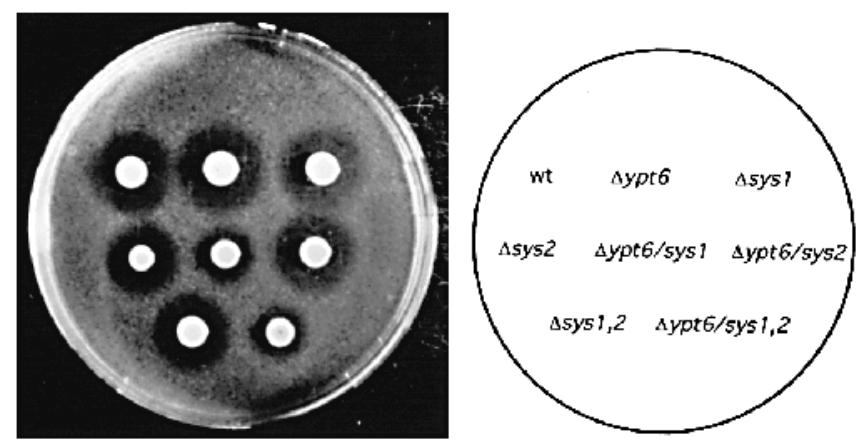

Fig. 5. Secretion of active $\alpha$-pheromone in various deletion mutants. $M A T \alpha$ strains carrying gene deletions as indicated were grown to stationary phase and after appropriate dilution, $5 \mu \mathrm{l}$ of cultures were spotted onto a lawn of the MATa supersensitive strain. The diameter of the growth-inhibitory zone (halo) is proportional to the amount of $\alpha$-pheromone secreted.

medium, but lack of the functional Kex2 endoprotease, which is located in the late Golgi compartment and participates in maturation of $\alpha$-pheromone precursor, leads to a defect in proteolytic maturation and the secretion of highly glycosylated precursor forms (Payne and Schekman, 1989).

Strains were labelled for 30 minutes with $\operatorname{Tran}^{35} \mathrm{~S}$-label and $\alpha$-pheromone was then immunoprecipitated from the culture medium. The immunoprecipitates were analysed by SDSPAGE. As shown in Fig. 6, most of the immunoreactive species detected in culture medium of ypt6/sys 1 null mutants comigrated with highly glycosylated $\alpha$-pheromone precursor (about $125 \mathrm{kDa}$ ) which is also secreted from kex 2 null mutants (compare lanes 1 and 5). Isogenic wild-type cells and cells of a sys 1 deletion strain secreted only mature $\alpha$-pheromone (Fig. 6 , lanes 2 and 4). In ypt6 null mutants, however, in addition to the mature $\alpha$-pheromone, highly glycosylated $\alpha$-pheromone was also secreted (Fig. 6, lane 3).

The result that ypt6/sys 1 null mutant cells secreted the highly glycosylated $\alpha$-pheromone precursor nearly exclusively suggests that a defect in halo-forming activity is due to a defect in $\alpha$-pheromone maturation rather than to a block in secretion. This result is in line with the demonstration that, in parallel experiments, intracellular accumulation of secreted invertase or $\alpha$-pheromone in ypt6/sys 1 null mutants at $30^{\circ} \mathrm{C}$ was negligible (data not shown).

\section{The Golgi-localized Kex2 protease is missorted to the vacuole in ypt6 deletion mutants}

The secretion of highly glycosylated $\alpha$-pheromone precursor from ypt6 and ypt6/sys 1 null mutants (Fig. 6) could be caused by reduced levels of Kex2p. To test this possibility, the steadystate levels of Kex2p were measured. Wild-type and mutants strains were transformed with the singlecopy plasmid pSN218 expressing a HA-tagged Kex2 protease (Nothwehr et al., 1995). Cellular proteins were prepared from each strain and Kex2p was detected by immunoblotting using antibodies specific for HA. Compared to wild-type cells, levels of Kex2p were markedly reduced in ypt6 and ypt6/sys 1 but not in sys 1 null mutant cells (Fig. 7A). Additional disruption of SYS1 in ypt6 null mutants seemed not to cause a synthetic defect, however. As the Kex2 protease appears to cycle between the late Golgi and a post-Golgi, endosome-like compartment and

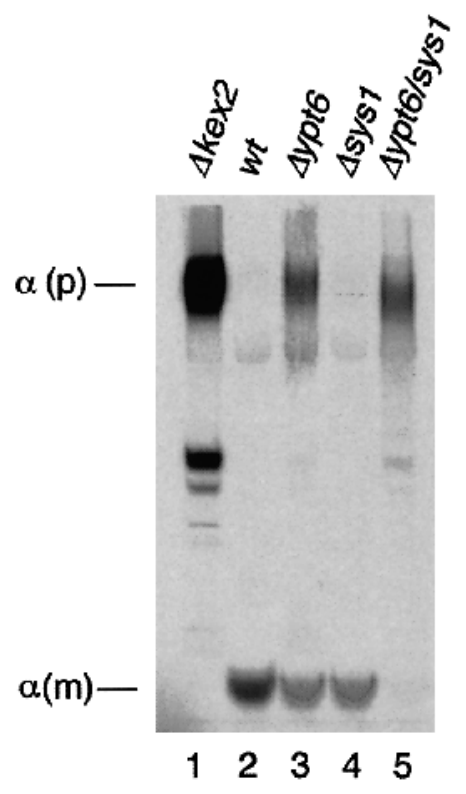

Fig. 6. Secretion of highly glycosylated $\alpha$-pheromone precursor in ypt6/sys 1 double deletion mutants. MAT $\alpha$ strains carrying gene deletions as indicated were grown to exponential phase and labelled for 30 minutes at $30^{\circ} \mathrm{C}$ with $\operatorname{Tran}^{35} \mathrm{~S}$-label. Culture media were collected and $\alpha$-pheromone was immunoprecipitated with anti- $\alpha$ pheromone antiserum and analysed by SDS-PAGE on $15 \%$ gels. $\alpha$ (p), highly glycosylated $\alpha$-pheromone precursor; $\alpha(\mathrm{m})$, mature $\alpha$ pheromone.

mutants defective in this cycling process missort Kex2p to the vacuoles (Wilsbach and Payne, 1993), Kex2p should be restored to wild-type levels in the ypt6 null mutants lacking functional vacuolar proteinases. As shown in Fig. 7B, this in fact was the case. Although the results we obtained in this study did somewhat vary from experiment to experiment, they clearly showed that in ypt6 null mutants, part of Kex2p was mislocalized to and degraded in the vacuole. This study also explains the inhibition of $\alpha$-pheromone maturation observed in mutant cells lacking both Ypt6p and Sys1p (Fig. 6).

\section{The missorting of CPY in ypt6 deletion mutants is enhanced by the additional disruption of SYS1 or SYS2}

To follow the intracellular traffic of another marker protein, processing and maturation of the soluble vacuolar proteinase CPY was analysed. As mentioned above, transport of CPY through the secretory pathway can be monitored by the appearance of three forms, a $67 \mathrm{kDa}$ ER form (p1CPY), a $69 \mathrm{kDa}$ Golgi-modified form (p2CPY) and the $61 \mathrm{kDa}$ mature form (mCPY) found in the vacuole. Sorting defects lead to the secretion and appearance of p2CPY in the extracellular space. Wild-type and mutant cells grown in YEPD to exponential phase were converted to spheroplasts, labelled for 15 minutes with $\operatorname{Tran}^{35} \mathrm{~S}$-label, and then chased for 30 minutes with an excess of unlabelled methionine and cysteine. After termination of the chase period, the intracellular (I) and extracellular (E) fractions were separated and the immunoprecipitated CPY species were analysed by SDS-PAGE.

In wild-type cells and in sys 2 null mutant cells, CPY was properly delivered to the vacuole as demonstrated by the 


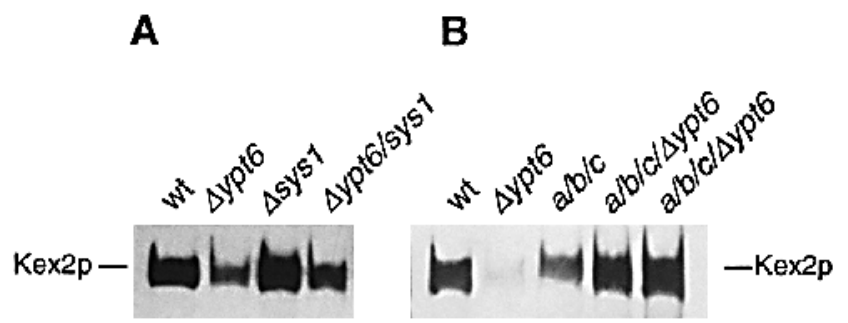

Fig. 7. Kex2p steady state levels in wild-type and ypt6 null mutants. (A) Cell extracts were prepared from cultures of wild-type, $\Delta y p t 6$, $\Delta$ sys 1 and $\Delta y p t 6 /$ sys 1 strains transformed with pSN218, and HAtagged Kex2p was analyzed by SDS-PAGE and immunoblotting. (B) Cell extracts were prepared from cultures of $P R A 1 / P R B 1 / P R C 1$ and $\mathrm{pra} 1-1 / \mathrm{prb} 1-1 / \mathrm{prc} 1-1$ versions of $y$ pt 6 null mtuants transformed with pSN218, and HA-tagged Kex2p was analyzed by SDS-PAGE and immunoblotting. $a / b / c$, pral-1/prbl-1/prcl-1.

presence of $\mathrm{mCPY}$ in intracellular fractions and by the absence of p2CPY in extracellular fractions (Fig. 8, lanes 1, 2, 7 and 8 ), whereas small but clearly detectable portions of p2CPY were missorted to the medium in ypt6 and sys 1 null mutants (Fig. 8, lanes 4 and 6). The quantity of secreted CPY in ypt6 and sys 1 null mutants was variable in different experiments, but portions of p2CPY (about 10-20\%) in extracellular fractions were always clearly detected. Significantly, the additional disruption of either SYS1 or SYS2 in ypt6 null mutants, particularly the disruption of $S Y S 1$, increased the ratio of external to internal CPY (compare lanes 4, 10 and 12 of Fig. 8), suggesting an aggravation of the sorting defect. Similar enhancement of the amounts of p2CPY in the extracellular fraction was also observed in sys $1 /$ sys 2 null mutants (compare lane 6, 8 and 14 of Fig. 8). Comparing the single and double disruption mutants, the CPY missorting defects were clearly more than additive. The rather slow maturation (the half-time for the maturation of CPY in wild-type cells is $\sim 6$ minutes) in wild-type and all other strains can be ascribed to the fact that spheroplasts were used in our experiments. Although in wildtype cells and in all single null mutant cells the majority of the intracellularly located CPY was found in its mature form after a chase period of 30 minutes, only about half of the total intracellular CPY was found in its mature form in $y p t 6 / s y s 1$ and sys 1/sys 2 null mutants. Whether the delay of CPY maturation in these mutants is a direct consequence of the lack of Ypt6 or

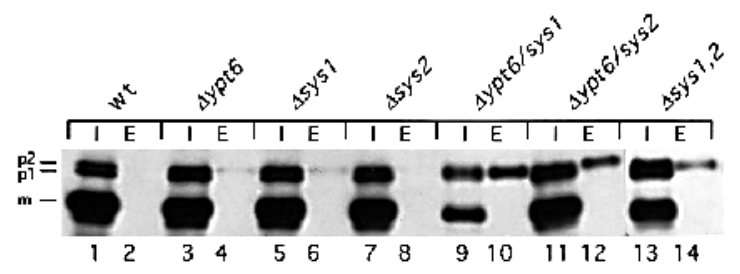

Fig. 8. Sorting of the vacuolar enzyme CPY. Wild-type cells and strains carrying gene deletions as indicated were grown to exponential phase, spheroplasted, labelled for 15 minutes at $30^{\circ} \mathrm{C}$ with Tran ${ }^{35} \mathrm{~S}-l a b e l$, and chased for 30 minutes at $30^{\circ} \mathrm{C}$. The labelled spheroplasts were separated into pellet (intracellular, I) and supernatant (extracellular, E) fractions. The presence of CPY in these fractions was determined by SDS-PAGE of the proteins immunoprecipitated with anti-CPY antibodies.
Sys proteins or a secondary effect resulting from the growth inhibition is an open question. It is clear, however, that correct sorting of p2CPY to the vacuole was increasingly impaired by the various double disruptions of YPT6, SYS1 and SYS2.

\section{The temperature-sensitive sec7-1 defect is complemented with multicopy SYS2}

The human homologue of Ypt6p, Rab6p, has been shown to be associated with the medial and trans-Golgi cisternae as well as with the TGN and to be involved in intra-Golgi protein transport (Goud et al., 1990; Antony et al., 1992; Martinez et al., 1994). To inquire into the possibility that Ypt6p in yeast is also active in Golgi transport, we investigated whether the SYS genes and/or YPT6 are able to complement conditional-lethal sec7 mutants. The Sec7 protein functions in the vesicular transport within and from the Golgi apparatus and is thought to play a role in coating of transport vesicles (Franzusoff and Schekman, 1989; Franzusoff et al., 1992). The temperaturesensitive sec7-1 mutant was transformed with multicopy vectors containing either of the SYS genes or YPT6. Of these genes, only $S Y S 2$ was able to complement the $\mathrm{Ts}^{-}$phenotype of sec7-1 when overexpressed (Fig. 9A). Furthermore, SYS2 on a multicopy plasmid could only suppress the $\mathrm{Ts}^{-}$phenotype of $\sec 7-1$ but not that of another allele, sec7-4 (Fig. 9B). From this, we concluded that SYS2 expresses not only ypt6 suppressor function but also an allele-specific sec7 suppressor function.

Additionally, we have also investigated whether high expression of the SYS genes or YPT6 could rescue other secretory or ypt mutants. The temperature-sensitive sec14-1, a mutant whose malfunction of a lipid transfer protein results in a severe late Golgi transport defect (Bankaitis et al., 1989, 1990), and a mutant lacking the Ypt51 GTPase involved in endocytotic protein transport (Horazdovsky et al., 1994; Singer-Krüger et al., 1994) were transformed with multicopy vectors containing each of the different SYS genes or YPT6. None of the genes was able to complement the $\mathrm{Ts}^{-}$phenotype

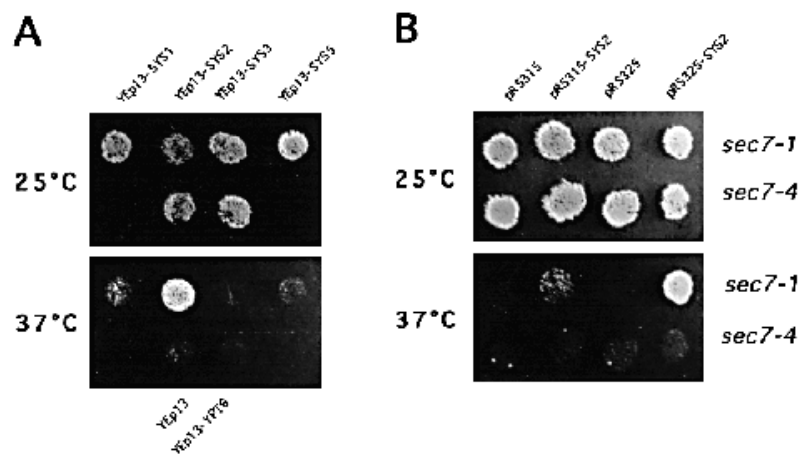

Fig. 9. Suppression of temperature-sensitive growth defects of a sec7-1 strain by multicopy SYS2. (A) sec7-1 strains transformed with the multicopy vector YEp13 without insert or with DNA fragments harbouring the different SYS genes or YPT6 were selected, replicaplated onto SD (-Leu) medium and incubated for 2 to 3 days at $25^{\circ} \mathrm{C}$ or $37^{\circ} \mathrm{C}$. (B) $\sec 7-1$ and $\sec 7-4$ strains were transformed with insertfree singlecopy (pRS315) or multicopy vector (pRS325) or with plasmids containing the subcloned SYS 2 gene, transformants were selected, replica-plated onto SD (-Leu) medium and incubated for 2 to 3 days at $25^{\circ} \mathrm{C}$ or $37^{\circ} \mathrm{C}$. 
of sec14-1 or ypt51 null mutant cells (data not shown). This indicates that the suppressor functions of the SYS genes are specific primarily for defects of ypt6 null mutants.

\section{Morphological alterations in single and double deletion mutants}

In all likelihood, Ypt6p and Sys proteins participate in membrane trafficking in some way or another. As many yeast mutants defective in intracellular protein transport exhibit defined alterations of biosynthetic organelles, we subjected various single and double deletion mutants to an ultrastructural analysis. We used potassium permanganate fixation and staining, as this procedure allows the easy inspection of membrane structures without the need of spheroplasting the yeast cells.

As had been previously observed (Hengst, 1992; L. Hengst and D. Gallwitz, unpublished), ypt6 null mutants, studied here in a different genetic background, had on average several small vacuoles instead of the large and single organelle found in wild-type cells. In addition, several other membrane-bound structures, about 150 to $300 \mathrm{~nm}$ in diameter, and small vesicles about 40 to $50 \mathrm{~nm}$ in size appeared to be larger in number than in wild-type cells (Fig. 10B). Single sys 1 or sys 2 deletion mutants resembled ypt6 null mutants except for the vacuoles which were like wild-type. Notably, ypt6/sys 1 double deletion cells contained highly fragmented vacuoles that were either empty or irregularly filled with electron dense material (Fig. 10D). In addition, apparently membrane-bounded, spherical structures, completely or partially filled with material more dense than the surrounding cytoplasm, accumulated in these mutants (Fig. 10C). In contrast to the vacuoles, we have not seen a clear unit membrane delimiting these structures which were of similar size as the fragmented vacuoles and often close to the nuclear membrane (Fig. 10C and F). These structures
Fig. 10. Morphological alterations in ypt6/sys 1 null mutant cells. Wild-type (A), ypt6 disruption (B) and ypt6/sys 1 double disruption cells $(\mathrm{C}, \mathrm{D})$ from cultures grown to early logarithmic phase were fixed with potassium permanganate and embedded in glycid ether. Silver sections were inspected in a Philips CM12 electron microscope. Two sections, approximately $900 \mathrm{~nm}$ apart, of a ypt6/sys 1 mutant cell show fragmented vacuoles (V) and spherical structures of similar size and unknown nature (designated S). Higher magnifications (in $\mathrm{E}$ and $\mathrm{F}$ ) document the different appearance of the membranes surrounding vacuoles and spherical structures, respectively, and the occasional association of S-structures and Golgi-like cisternae (G). Other membrane-bound structures augmented in ypt6 null mutants are indicated by arrowheads. M, mitochondria; E, endoplasmic reticulum; N, nucleus. Bars, $1 \mu \mathrm{m}$ (D); $200 \mathrm{~nm}(\mathrm{~F})$.
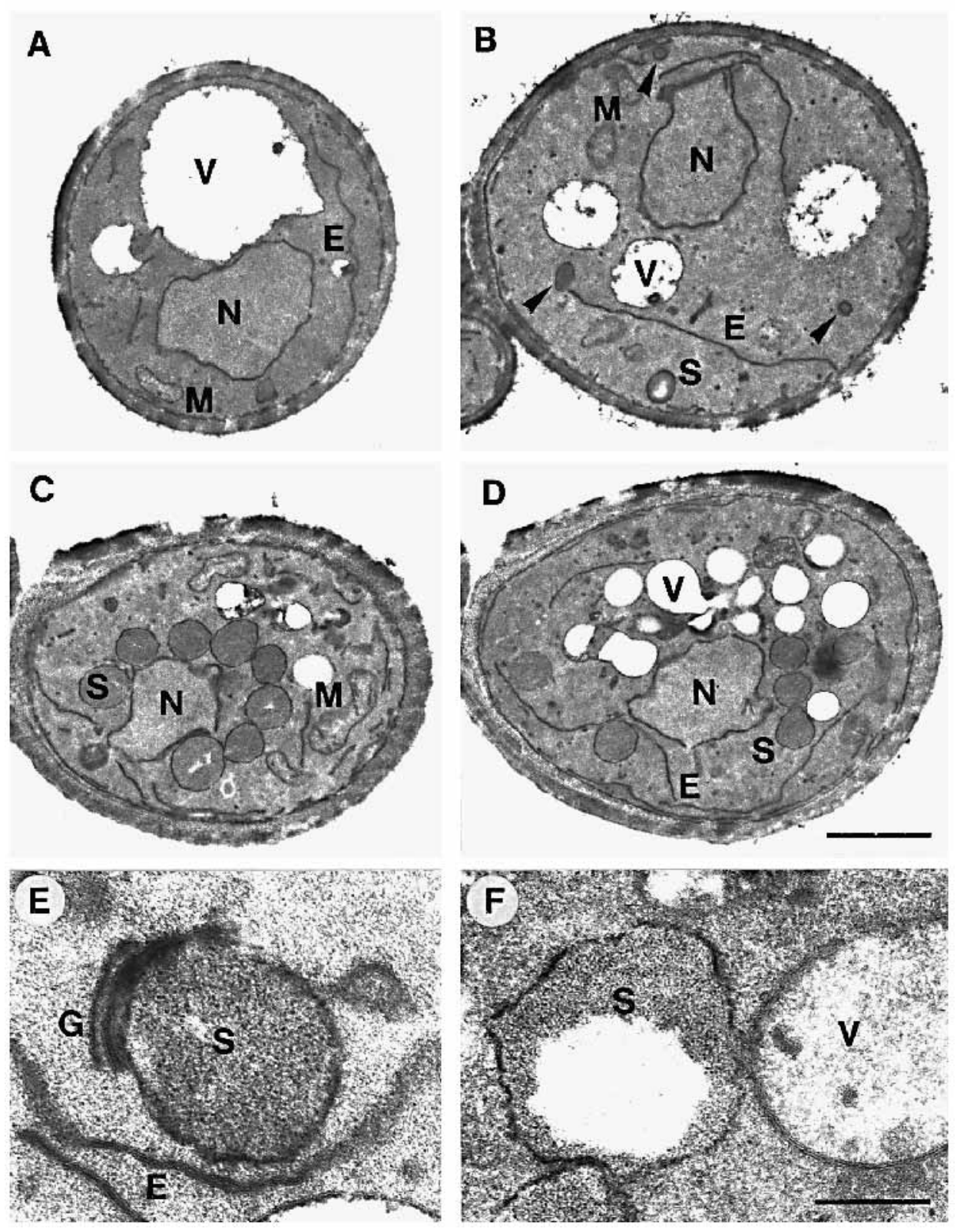
were not defective mitochondria seen in rho mutants, as normal mitochondria with typical cristae could be observed in the ypt6/sys 1 mutant cells (Fig. 10C). Occasionally, Golgi-like cisternae delimited by a unit membrane were observed adjacent to these organelles of unknown nature (Fig. 10E).

\section{DISCUSSION}

The fact that the disruption of YPT6 results in the partial missorting of vacuolar proteinase CPY (Hengst, 1992; L. Hengst and D. Gallwitz, unpublished), together with the function of Rab6p, the mammalian counterpart of Ypt6p, in the transport between Golgi compartments (Martinez et al., 1994), led us to assume a similar role for Ypt6p in yeast.

In a search for component(s) that interact with Ypt6p or otherwise substitute for the loss of functional Ypt6p, we succeeded in isolating four multicopy suppressors (SYS1, 2, 3, 5 ) that could suppress the Ts ${ }^{-}$growth phenotype of ypt6 null mutants. All SYS genes were able to also suppress, at least in part, the CPY missorting defect of ypt6 deletion strains. Although enhanced expression of the SYS2 gene was not as effective as the other multicopy suppressors in curing of ypt6 null mutants, SYS2 overexpression led to the suppression of the $\mathrm{Ts}^{-}$phenotype of sec7-1, a mutant defective in protein transport within and from the Golgi complex (Franzusoff and Schekman, 1989). This suppression was allele-specific, as the sec7-4 mutant could not be rescued from temperature sensitivity.

The allele-specific suppression of the $\sec 7$ mutation by the enhanced expression of SYS2 may indicate a direct physical interaction between Sec7p and Sys2p. This suppression could also mean that sec7-1 is simply less defective than sec7-4. If this was the case, the allele-specificity observed would not necessarily imply a direct physical interaction between Sys $2 p$ and Sec 7p. Instead, the suppression of sec $7-1$ could be due to a substitutional function of Sys $2 p$, which would argue for Sec7p and Sys $2 p$ playing a role in the same transport step. As Sec7p is involved in transport in and from the Golgi, perhaps by functioning in the coating of transport vesicles (Franzusoff et al., 1992), the genetic interaction of SEC7 and SYS2 is an indication for Sys2p participating in a Golgi-associated transport reaction. It should be noted here that high expression of the other SYS genes or of YPT6 could not rescue the conditionally lethal sec7 mutants.

The Ypt6 GTPase is not essential for yeast cell viability at $30^{\circ} \mathrm{C}$ (Hengst, 1992; L. Hengst and D. Gallwitz, unpublished). Likewise, the deletion of either the SYS1 or the SYS2 gene did not alter cell growth. However, the disruption of SYS1 or SYS2 in a ypt6 deletion strain led to a slow-down of cell growth and to an aggravation of the CPY missorting defect observed in single ypt6 null mutants. The disruption of SYS1 alone and in combination with a deletion of YPT6 resulted in more severe defects than the inactivation of $S Y S 2$ or the simultaneous deletion of SYS2 and YPT6. Notably, in $\Delta y p t 6 / s y s 1$ double and $\Delta y p t 6 / s y s 1 / s y s 2$ triple null mutants, the secretion of $\alpha$-factor appeared to be inhibited. As opposed to this, there was only a marginal intracellular accumulation of secreted invertase in ypt6/sys 1 and ypt6/sys $1 /$ sys 2 null mutants at $30^{\circ} \mathrm{C}$. The significantly smaller halos produced by mutant cells which lack both the Ypt6 GTPase and the Sys1 protein could also be explained by a missorting of Kex $2 p$. This, in fact, appears to be the case. The Kex 2 protease participates in the maturation of $\alpha$ pheromone proforms and has been shown to be mislocalized to the plasma membrane in clathrin-defective yeast mutants (Payne and Schekman, 1989; Seeger and Payne, 1992), possibly due to an interference with transport from an endosomal to the distal Golgi compartment between which the Kex 2 protease appears to cycle. Whereas sys 1 deletion mutant cells secreted perfectly processed $\alpha$-factor, ypt6 deletion led to the secretion of highly glycosylated, unprocessed $\alpha$-factor precursor in addition to the mature form. More importantly, cells of a sys1/ypt6 double deletion mutant secreted the unprocessed $\alpha$-pheromone nearly exclusively, indicating an inefficient cleavage of the $\alpha$-factor proform by the Kex 2 protease. Secretion of $\alpha$-factor or its unprocessed precursor was not affected significantly in the deletion mutants. In support of the assumption that Kex 2 p cycling between the late Golgi and an endosomal compartment was affected in ypt6 and ypt6/sys 1 deletion mutants is our finding that in these, but not in the sys 1 deletion mutants, the amount of Kex 2 protease at steady-state was significantly reduced as compared to that of wild-type cells. A study with vacuolar protease mutants revealed that this reduction resulted from a missorting of Kex2p to the vacuole. As the CPY receptor has been demonstrated to also cycle between the late Golgi and an endosome compartment (Cereghino et al., 1995; Cooper and Stevens, 1996), an interference with this transport route would also nicely explain the missorting of CPY to the plasma membrane in ypt6 and various ypt6/sys mutants.

The synthetic negative effects on cell growth, vacuolar protein sorting and on $\alpha$-factor maturation in various deletion mutants is a clear indication for Ypt6p, Sys $1 p$ and Sys $2 p$ acting in the same protein transport pathway. It seems reasonable to assume then that the role of all three proteins is linked to the functional integrity of anterograde/retrograde transport routes connecting the late Golgi compartment and an endosomal organelle. This assumption would somewhat deviate from the currently discussed role of the Rab6 GTPase in mammalian cells which appears to be involved in intra-Golgi transport (Martinez et al., 1994).

GTPases of the Ypt protein family which act at defined steps of the secretory pathway, like Ypt1p (Segev et al., 1988; Schmitt et al., 1988), Sec4p (Salminen and Novick, 1987) and Ypt31p/Ypt32p (M. Benli, F. Döring, D. G. Robinson and D. Gallwitz, unpublished) are essential for yeast cell viability. In contrast, Ypt GTPases with a function in the endocytotic pathway, like Ypt7p (Wichmann et al., 1992) or Ypt51p/Ypt52p/Ypt53p (Singer-Krüger et al., 1994) are dispensable for cell growth as is Ypt6p. As in addition, ypt7 and ypt51 mutants missort vacuolar CPY, one might argue that Ypt6p and the suppressor proteins described here might fulfill their function at some step of the endocytotic pathway. Although we cannot at present exclude such a possibility, the genetic interaction of SYS1, SYS2 and YPT6 together with the $\alpha$-factor maturation defect of ypt6/sys 1 deletion strains and the genetic interaction of SYS2 with SEC7 are an indication of Ypt6p, Sys1p and Sys2p being involved in Golgi-associated function, most likely in vesicular transport from the Golgi to an endocytotic compartment, or else from an endosome-like organelle back to a distal Golgi compartment. At present we cannot exclude the possibility that, as proposed for mammalian 
Rab6p (Martinez et al., 1994), Ypt6p and the suppressor proteins described here act in retrograde Golgi transport. There is in fact no evidence for retrograde intra-Golgi transport being essential for yeast cell viability.

In a previous study it was observed that ypt6 null mutants on average contained smaller vacuoles than wild-type cells (Hengst, 1992; L. Hengst and D. Gallwitz, unpublished). This and the severe fragmentation of vacuoles in ypt6/sys 1 double and $y p t 6 / s y s 1 / s y s 2$ triple deletion strains might represent secondary effects resulting from Golgi transport defects. As the vacuole in yeast appears to be a rather dynamic organelle and several vacuolar protein sorting (vps) mutants exhibit structural abnormalities of the vacuole (Raymond et al., 1992b), it will be difficult to pinpoint the molecular details underlying the fragmentation of the vacuole in the ypt6/sys 1 disruption mutants. We do not know whether the spherical structures of similar size as the fragmented vacuoles which appeared in rather large numbers in these mutants are related to vacuoles. However, in thin sections with a clearly discernable vacuolar membrane, we have never observed a unit membrane comprising these structures. The significance of Golgi-like cisternae attached to several of these structures is also unclear at present. Immunoelectron microscopic visualization of known yeast organelle marker proteins might help to clarify the origin of these structures.

The amino acid sequence of Sys1p suggests that it is an integral membrane protein. Although no other protein with significant homology was found in presently available databases, Sys $1 p$ with its four putative membrane-spanning domains (Fig. 3A) appears to be structurally related to the recently discovered synaptic vesicle protein synaptogyrin (Stenius et al., 1995). The two proteins have comparable molecular masses, their putative transmembrane domains are similarly spaced within the protein molecules, and the C-terminal regions of both proteins are rich in aspartic/glutamic acid, glycine, proline and glutamine that together comprise more than $40 \%$ of the amino acid residues. In contrast to synaptogyrin, however, the C-terminal region of Sys $1 p$ is devoid of tyrosines. Although we have not studied the membrane topology of Sys1p, considering its admittedly limited similarity with synaptogyrin, one might speculate that Sys1p is a resident of transport vesicles carrying cargo between and/or from the Golgi apparatus. Sys1p might therefore belong to a growing family of proteins that reside on different trafficking organelles, span the membrane four times and whose $\mathrm{C}$ - and N-termini are facing the cytoplasm (Stenius et al., 1995).

According to its published sequence (GenBank accession number X59720), Sys2p is a hydrophilic protein with similarity to Slf1p, another yeast protein of nearly identical length and unknown function. As various vesicular transport steps involving Ypt/Rab GTPases require the formation of multiprotein complexes for vesicle docking and fusion (Bowser et al., 1992; Søgaard et al., 1994), it could well be that Sys2p as well as Sys1p are components of such complexes. As there is a genetic interaction between $S Y S 2$ and SEC7, Sys2p might also interact with Sec7p. Whether this is so has to await future biochemical analyses of these proteins.

We are indebted to Dr Hans-Heinrich Trepte for performing the EM analysis, to Drs S. D. Emr and Bruce Horazdovsky for providing plasmid pBHY11 and yeast strains and to Dr T. H. Stevens for providing plasmid pSN218. We thank Dr Reiner Grabowski for advice and Hans-Peter Geithe for synthesizing oligonucleotides. This work was supported in part by grants to D. G. from the Deutsche Forschungsgemeinschaft and the Fonds der Chemischen Industrie. M. T. was supported by a Max-Planck Fellowship.

\section{REFERENCES}

Aalto, M. K., Ronne, H. and Keränen, S. (1993). Yeast syntaxins Sso1p and Sso2p belong to a family of related membrane proteins that function in vesicular transport. EMBO J. 12, 4095-4104.

Antony, C., Cibert, C., Géraud, G., Santa Maria, A., Maro, B., Mayau, V. and Goud, B. (1992). The small GTP-binding protein rab6p is distributed from medial Golgi to the trans-Golgi network as determined by a confocal microscopic approach. J. Cell Sci. 103, 785-796.

Banfield, D. K., Lewis, M. J. and Pelham, H. R. B. (1995). A SNARE-like protein required for traffic through the Golgi complex. Nature 375, 806-809.

Bankaitis, V. A., Malehorn, D. E., Emr, S. D. and Greene, R. (1989). The Saccharomyces cerevisiae SEC14 gene encodes a cytosolic factor that is required for transport of secretory proteins from the yeast Golgi complex. $J$. Cell Biol. 108, 1271-1281.

Bankaitis, V. A., Aitken, J. R., Cleves, A. E. and Dowhan, W. (1990). An essential role for a phospholipid transfer protein in yeast Golgi function. Nature 347, 561-562.

Botstein, D., Falco, S. C., Stewart, S. E., Brennan, M., Scherer, S., Stinchcomb, D. T., Struhl, K. and Davis, R. W. (1979). Sterile host yeasts (SHY): a eukaryotic system of biological containment for recombinant DNA experiments. Gene 8, 17-24.

Bowser, R., Müller, H., Govindan, B. and Novick, P. (1992). Sec8p and Sec15p are components of a plasma membrane-associated $19.5 \mathrm{~s}$ particle that may function downstream of Sec4p to control exocytosis. J. Cell Biol. 118, 1041-1056.

Brennwald, P., Kearns, B., Champion, K., Keränen, S., Bankaitis, V. and Novick, P. (1994). Sec9 is a SNAP-25-like component of a yeast SNARE complex that may be the effector of Sec4 function in exocytosis. Cell 79, 245-258.

Bretscher, M. S. and Munro, S. (1993). Cholesterol and the Golgi apparatus. Science 261, 1280-1281.

Cereghino, J. L., Marcusson, E. G. and Emr, S. D. (1995). The cytoplasmic tail domain of the vacuolar protein sorting receptor Vps10p and a subset of $V P S$ gene products regulate receptor stability, function, and localization. Mol. Biol. Cell 6, 1089-1102.

Cooper, A. A. and Stevens, T. H. (1996). Vps10p cycles between the lateGolgi and prevacuolar compartments in its function as the sorting receptor for multiple yeast vacuolar hydrolases. J. Cell Biol. 133, 529-541.

Dascher, C., Ossig, R., Gallwitz, D. and Schmitt, H. D. (1991). Identification and structure of four yeast genes $(S L Y)$ that are able to suppress the functional loss of YPT1, a member of the RAS superfamily. Mol. Cell. Biol. 11, 872-885.

Franzusoff, A. and Schekman, R. (1989). Functional compartments of the yeast Golgi apparatus are defined by the sec7 mutation. EMBO J. 8, 26952702.

Franzusoff, A., Lauzé, E. and Howell, K. E. (1992). Immuno-isolation of Sec 7 p-coated transport vesicles from the yeast secretory pathway. Nature 355, 173-175.

Goud, B., Zahraoui, A., Tavitian, A. and Saraste, J. (1990). Small GTPbinding protein associated with Golgi cisternae. Nature 345, 553-556.

Grabowski, R., Yoo, J.-S. and Gallwitz, D. (1995). The role of monomeric GTPases in intracellular protein traffic in yeast. Mol. Cells $\mathbf{5}, 399-405$.

Hengst, L., Lehmeier, T. and Gallwitz, D. (1990). The $r y h l$ gene in the fission yeast Schizosaccharomyces pombe encoding a GTP-binding protein related to ras, rho and ypt: structure, expression and identification of its human homologue. EMBO J. 9, 1949-1955.

Hengst, L. (1992). Struktur und Funktion der GTP-bindenden, ras-verwandten Ryh1-Proteine aus Hefen. Dissertation zur Erlangung des Doktorgrades der Naturwissenschaft (PhD thesis), Philipps-Universität Marburg/Lahn.

Horazdovsky, B. F., Busch, G. R. and Emr, S. D. (1994). VPS 21 encodes a rab5-like GTP binding protein that is required for the sorting of yeast vacuolar proteins. EMBO J. 13, 1297-1309.

Ito, H., Fukuda, Y., Murata, K. and Kimura, A. (1983). Transformation of intact yeast cells treated with alkali cations. J. Bacteriol. 153, 163-168.

Jones, D. T., Taylor, W. R. and Thornton, J. M. (1994). A model recognition 
approach to the prediction of all-helical membrane protein structure and topology. Biochemistry 33, 3038-3049.

Julius, D., Blair, L., Brake, A., Sprague, G. and Thorner, J. (1983). Yeast $\alpha$ factor is processed from a larger precursor polypeptide: the essential role of a membrane-bound dipeptidyl aminopeptidase. Cell 32, 839-852.

Kaiser, C. A. and Schekman, R. (1990). Distinct sets of SEC genes govern transport vesicle formation and fusion early in the secretory pathway. Cell 61, 723-733.

Klionsky, D. J., Herman, P. K. and Emr, S. D. (1990). The fungal vacuole: composition, function and biogenesis. Microbiol. Rev. 54, 266-292.

Koonin, E. V., Bork, P. and Sander, C. (1994). Yeast chromosome III: new gene functions. EMBO J. 13, 493-503.

Kyte, J. and Doolittle, R. F. (1982). A simple method for displaying the hydropathic character of a protein. J. Mol. Biol. 157, 105-132.

Martinez, O., Schmidt, A., Salaméro, J., Hoflack, B., Roa, M. and Goud, B. (1994). The small GTP-binding protein rab6 functions in intra-Golgi transport. J. Cell Biol. 6, 1575-1588.

Nothwehr, S. F., Conibear, E. and Stevens, T. H. (1995). Golgi and vacuolar membrane proteins reach the vacuole in vps1 mutant yeast cells via the plasma membrane. J. Cell Biol. 129, 35-46.

Novick, P., Ferro, S. and Schekman, R. (1981). Order of events in the yeast secretory pathway. Cell $\mathbf{2 5}, 461-469$

Oliver, S. G., van der Aart, Q. J. M., Agostini-Carbone, M. L., Aigle, M., Alberghina, M., Alexandraki, D., Antoine, G., Anwar, R., Ballesta, J. P. G., Benit, P. et al. (1992). The complete DNA sequence of yeast chromosome III. Nature 357, 38-46.

Ossig, R., Dascher, C., Trepte, H.-H., Schmitt, H. D. and Gallwitz, D. (1991). The yeast $S L Y$ gene products, suppressors of defects in the essential GTP-binding YPT1 protein, may act in endoplasmic reticulum-to-Golgi transport. Mol. Cell. Biol. 11, 2980-2993.

Oyler, G. A., Higgins, G. A., Hart, R. A., Battenberg, E., Billingsley, M., Bloom, F. E. and Wilson, M. C. (1989). The identification of a novel synaptosomal-associated protein, SNAP-25, differentially expressed by neuronal subpopulations. J. Cell Biol. 109, 3039-3052.

Payne, G. S. and Schekman, R. (1989). Clathrin: a role in the intracellular retention of a Golgi membrane protein. Science 245, 1358-1365.

Raymond, C. K., Roberts, C. J., Moore, K. E., Howald, I. and Stevens, T. H. (1992a). Biogenesis of the vacuole in Saccharomyces cerevisiae. Int. Rev. Cytol. 139, 59-120.

Raymond, C. K., Howald-Stevenson, I., Vater, C. A. and Stevens, T. H. (1992b). Morphological classification of the yeast vacuolar protein sorting mutants: evidence for a prevacuolar compartment in class $\mathrm{E}$ vps mutants. Mol. Biol. Cell 3, 1389-1402.

Robinson, J. S., Klionsky, D. J., Banta, L. M. and Emr, S. D. (1988). Protein sorting in Saccharomyces cerevisiae: isolation of mutants defective in the delivery and processing of multiple vacuolar hydrolases. Mol. Cell. Biol. 8 , 4936-4948.
Rose, M. D., Winston, F. and Hieter, P. (1990). Methods in Yeast Genetics. A Laboratory Course Manual. Cold Spring Harbor Laboratory Press, Cold Spring Harbor, NY.

Rothman, J. E. (1994). Mechanisms of intracellular protein transport. Nature 372, 55-63.

Salminen, A. and Novick, P. J. (1987). A ras-like protein is required for a post-Golgi event in yeast secretion. Cell 49, 527-538.

Schmitt H. D., Puzicha, M. and Gallwitz, D. (1988). Study of a temperaturesensitive mutant of the ras-related $Y P T 1$ gene product in yeast suggests a role in the regulation of intracellular calcium. Cell 53, 635-647.

Seeger, M. and Payne, G. S. (1992). Selective and immediate effects of clathrin heavy chain mutations on Golgi membrane protein retention in Saccharomyces cerevisiae. J. Cell Biol. 118, 531-540.

Segev, N., Mulholland, J. and Botstein, D. (1988). The yeast GTP-binding YPT1 protein and a mammalian counterpart are associated with the secretion machinery. Cell 52, 915-924.

Sikorski, R. S. and Hieter, P. (1989). A system of shuttle vectors and yeast host strains designed for efficient manipulation of DNA in Saccharomyces cerevisiae. Genetics 122, 19-27.

Singer-Krüger, B., Stenmark, H., Düsterhöft, A., Philippsen, P., Yoo, J.-S., Gallwitz, D. and Zerial, M. (1994). Role of three Rab5-like GTPases, Ypt51p, Ypt52p, and Ypt53p, in the endocytic and vacuolar protein sorting pathways of yeast. J. Cell Biol. 125, 283-298.

Søgaard, M., Tani, K., Ye, R. R., Geromanos, S., Tempst, P., Kirchhausen, T., Rothman, J. E. and Söllner, T. (1994). A Rab protein is required for the assembly of SNARE complexes in the docking of transport vesicles. Cell 78, 937-948.

Söllner, T. (1995). SNAREs and targeted membrane fusion. FEBS Lett. 369, 80-83.

Stack, J. H., Horazdovsky, B. and Emr, S. D. (1995). Receptor-mediated protein sorting to the vacuole in yeast: roles for a protein kinase, a lipid kinase and GTP-binding proteins. Annu. Rev. Cell. Dev. Biol. 11, 1-33.

Stenius, K., Janz, R., Südhof, T. C. and Jahn, R. (1995). Structure of Synaptogyrin (p29) defines novel synaptic vesicle protein. J. Cell Biol. 131, 1801-1809.

Wichmann, H., Hengst, L. and Gallwitz, D. (1992). Endocytosis in yeast: evidence for the involvement of a small GTP-binding protein (Ypt7p). Cell 71, 1131-1142.

Wilsbach, K. and Payne, G. S. (1993). Vps1p, a member of the dynamin GTPase family, is necessary for Golgi membrane protein retention in Saccharomyces cerevisiae. EMBO J. 12, 3049-3059.

Zerial, M. and Stenmark, H. (1993). Rab GTPases in vesicular transport. Curr. Opin. Cell Biol. 5, 613-620.

(Received 26 March 1996 - Accepted 9 July 1996) 